\title{
Correction: Michielsen, I., et al. Altering Conversion and Product Selectivity of Dry Reforming of Methane in a Dielectric Barrier Discharge by Changing the Dielectric Packing Material. Catalysts 2019, 9, 51
}

\author{
Inne Michielsen, Yannick Uytdenhouwen (D), Annemie Bogaerts (D) and Vera Meynen *(D) \\ Department of Chemistry, University of Antwerp, Universiteitsplein 1, B-2610 Wilrijk, Belgium; \\ Inne.michielsen@gmail.com (I.M.); Yannick.uytdenhouwen@uantwerpen.be (Y.U.); \\ Annemie.Bogaerts@uantwerpen.be (A.B.) \\ * Correspondence: vera.meynen@uantwerpen.be
}

Received: 19 November 2020; Accepted: 25 November 2020; Published: 30 November 2020

check for updates

We have found some inadvertent errors in our paper published in Catalysts [1]. Amendments need to be made to Figure 1 and the sentences referring to the comparison of $\mathrm{CO}_{2}$ conversion in DRM (dry reforming of methane) versus the previously published $\mathrm{CO}_{2}$ splitting data [2]. Indeed, there were some mistakes in the datapoints in the original Figure 1, referring to previously published results from $\mathrm{CO}_{2}$ splitting [2], caused by copy-pasting datapoints in the layout of the figure, with incorrect ordering of the datapoints. The datapoints on $\mathrm{CO}_{2}$ conversion in DRM, as obtained for the original article [1], were however correct and remain unaltered.

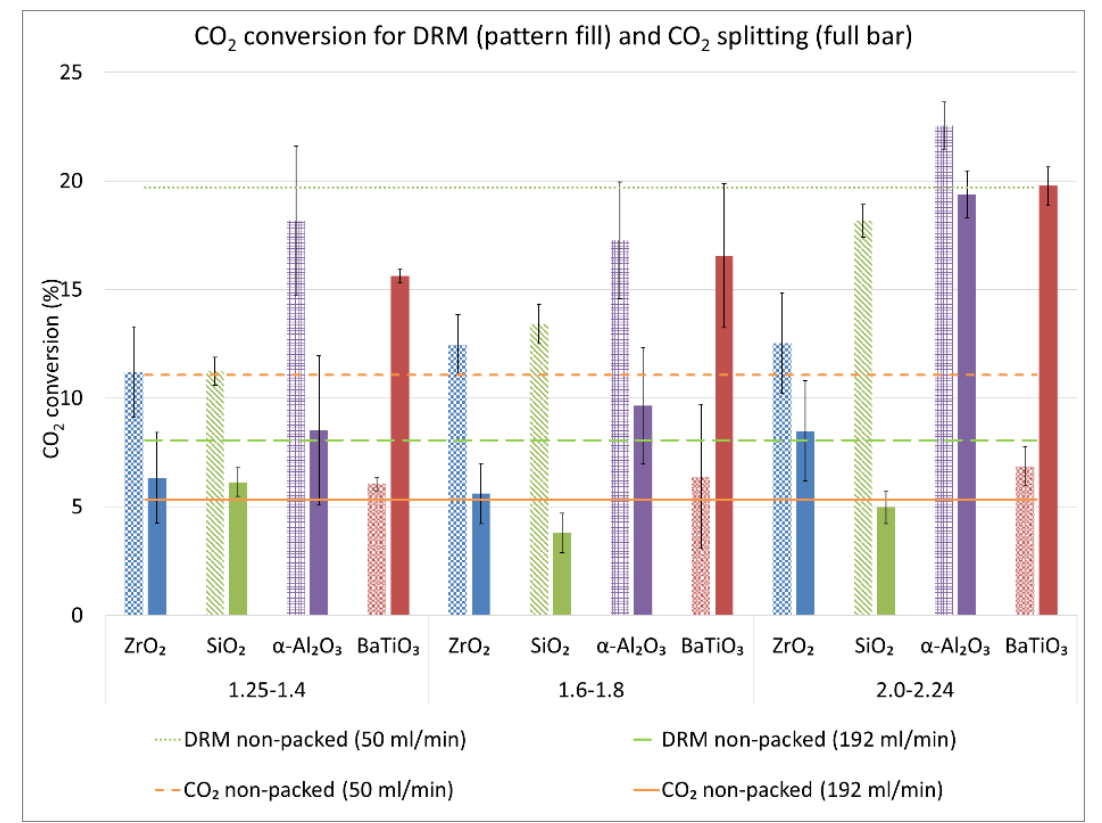

Figure 1. $\mathrm{CO}_{2}$ conversion for different sphere sizes and materials, compared to the results for the non-packed reactor, at the same flow rate $(50 \mathrm{~mL} / \mathrm{min})$ and at the same residence time $(5.52 \mathrm{~s}$; flow rate of $192 \mathrm{~mL} / \mathrm{min}$ ), all at $23 \mathrm{kHz}$ frequency, in a $4.5 \mathrm{~mm}$ gap and a set 100 Watt power for both DRM (dry reforming of methane) and pure $\mathrm{CO}_{2}$ splitting. The bars with pattern fill show the results for DRM, whereas the full bars show the correct results for $\mathrm{CO}_{2}$ splitting, obtained from our previous work [2].

The corrected Figure 1 should be as follows: 
In Figure 1, all datapoints with full bars, referring to $\mathrm{CO}_{2}$ splitting data from [2], have been corrected, except for two values that were correct (1.25-1.4 $\mathrm{mm} \mathrm{ZrO}_{2}$ and 2.0-2.4 $\mathrm{mm} \mathrm{BaTiO}_{3}$ ).

To show the numerical data, the differences between the mistake in the datapoints and the corrected data from Figure 1 are provided in Table 1.

Table 1. The correct datapoints of $\mathrm{CO}_{2}$ conversion in the $\mathrm{CO}_{2}$ splitting reaction from [2] (green corrected data column) in relation to those that were mistakenly put (previous data with error) in Figure 1. Those that cause the largest differences are marked in red.

\begin{tabular}{llll}
\hline & & Corrected Data & Previous Data with Error \\
\hline Material & Size (mm) & $\mathbf{C O}_{2}$ Conversion (\%) & $\mathbf{C O}_{2}$ Conversion (\%) \\
\hline $\mathrm{ZrO}_{2}$ & $1.25-1.4$ & 6.32 & 6.32 \\
$\mathrm{SiO}_{2}$ & $1.25-1.4$ & 6.13 & 5.60 \\
$\alpha-\mathrm{Al}_{2} \mathrm{O}_{3}$ & $1.25-1.4$ & 8.51 & 8.49 \\
$\mathrm{BaTiO}_{3}$ & $1.25-1.4$ & 15.61 & 6.13 \\
$\mathrm{ZrO}_{2}$ & $1.6-1.8$ & 5.60 & 3.78 \\
$\mathrm{SiO}_{2}$ & $1.6-1.8$ & 3.78 & 4.98 \\
$\alpha-\mathrm{Al}_{2} \mathrm{O}_{3}$ & $1.6-1.8$ & 9.65 & 8.51 \\
$\mathrm{BaTiO}_{3}$ & $1.6-1.8$ & 16.56 & 9.65 \\
$\mathrm{ZrO}_{2}$ & $2.0-2.4$ & 8.49 & 19.37 \\
$\mathrm{SiO}_{2}$ & $2.0-2.4$ & 4.98 & 15.61 \\
$\alpha-\mathrm{Al}_{2} \mathrm{O}_{3}$ & $2.0-2.4$ & 19.37 & 16.56 \\
$\mathrm{BaTiO}_{3}$ & $2.0-2.4$ & 19.77 & 19.77 \\
\hline
\end{tabular}

Besides Figure 1, also some parts of the text need to be amended, where a comparison is made between the data of $\mathrm{CO}_{2}$ conversion in DRM (dry reforming of methane) versus the corrected $\mathrm{CO}_{2}$ splitting data [2], based on Figure 1.

In the text, the sentence on page 16, in penultimate paragraph, "Our experiments clearly reveal that the absolute $\mathrm{CO}_{2}$ conversion is also higher for DRM than for $\mathrm{CO}_{2}$ splitting, with the exception of $\mathrm{BaTiO}_{3}$ and 2.0-2.24 $\mathrm{mm} \mathrm{ZrO}_{2}$ packing" should read, "Our experiments clearly reveal that the absolute $\mathrm{CO}_{2}$ conversion is also higher for DRM than for $\mathrm{CO}_{2}$ splitting, with the exception of $\mathrm{BaTiO}_{3}$ ".

In the text, the last paragraph of Section 2.1 on page 16, starting with, "For DRM in the packed reactor, the $\mathrm{CO}_{2}$ conversion is always higher when using $\mathrm{SiO}_{2}$ and $\alpha-\mathrm{Al}_{2} \mathrm{O}_{3}$ packing materials ..." should read, "For DRM in the packed reactor, the $\mathrm{CO}_{2}$ conversion is always higher when using $\mathrm{SiO}_{2}$, $\mathrm{ZrO}_{2}$ and $\alpha-\mathrm{Al}_{2} \mathrm{O}_{3}$ packing materials than for pure $\mathrm{CO}_{2}$ splitting. However, the enhancement of the $\mathrm{CO}_{2}$ conversion due to $\mathrm{CH}_{4}$ depends on the size and chemistry of the spherical packing material. Finally, $\mathrm{CH}_{4}$ addition has a clearly negative effect on all $\mathrm{BaTiO}_{3}$ packing materials. Thus, although $\mathrm{BaTiO}_{3}$ in general performs best for $\mathrm{CO}_{2}$ splitting, compared to the other packing materials, it yields the worst results for DRM".

In the text, the sentence on page 25, in penultimate paragraph preceding the Materials and Methods, starting with "Nevertheless, the above reasoning is only a first hypothesis, as other materials exhibiting a lower $\mathrm{CO}_{2}$ conversion in case of DRM versus pure $\mathrm{CO}_{2}$ splitting (i.e., $\mathrm{ZrO}_{2}$ with bead size of 2.0-2.24 mm) ..." is no longer necessary as the $\mathrm{ZrO}_{2}$ splitting data do not present lower $\mathrm{CO}_{2}$ conversion in DRM versus pure $\mathrm{CO}_{2}$ splitting in the corrected Figure 1, which thus eliminates the anomaly in our theory. Of course, it is still true that further experiments and extensive modeling are needed to substantiate the results further. The text should thus read: "Nevertheless, this is still a hypothesis which needs further experimental and modeling proof to substantiate it and reveal the underlying mechanisms".

We regret that the comparative data for $\mathrm{CO}_{2}$ splitting from the previous publication [2] in Figure 1 were represented in the wrong way. However, all new data on DRM were correct. Fortunately, this error has no impact on the overall results and/or conclusions reported in the original paper and it even 
solves some deviation in our hypotheses. Hence, the conclusions made in the original paper remain valid. We apologize for any inconvenience caused to the readers.

Conflicts of Interest: The authors declare no conflict of interest.

\section{References}

1. Michielsen, I.; Uytdenhouwen, Y.; Bogaerts, A.; Meynen, V. Altering conversion and product selectivity of dry reforming of methane in a dielectric barrier discharge by changing the dielectric packing material. Catalysts 2019, 9, 51. [CrossRef]

2. Michielsen, I.; Uytdenhouwen, Y.; Pype, J.; Michielsen, B.; Mertens, J.; Reniers, F.; Meynen, V.; Bogaerts, A. $\mathrm{CO}_{2}$ dissociation in a packed bed DBD reactor: First steps towards a better understanding of plasma catalysis. Chem. Eng. J. 2017, 326, 477-488. [CrossRef]

Publisher's Note: MDPI stays neutral with regard to jurisdictional claims in published maps and institutional affiliations.

(C) 2020 by the authors. Licensee MDPI, Basel, Switzerland. This article is an open access article distributed under the terms and conditions of the Creative Commons Attribution (CC BY) license (http://creativecommons.org/licenses/by/4.0/). 